\title{
Feeding, bioenergetics and growth in the common jellyfish Aurelia aurita and two hydromedusae, Sarsia tubulosa and Aequorea vitrina
}

\author{
Lene Friis Møller*, Hans Ulrik Riisgård \\ Marine Biological Research Centre, University of Southern Denmark, Hindsholmvej 11, 5300 Kerteminde, Denmark
}

\begin{abstract}
We assessed feeding and growth of the common jellyfish Aurelia aurita and 2 hydromedusae, Sarsia tubulosa and Aequorea vitrina, by examining the effect of temperature, medusa size, prey concentration and prey species on feeding and growth. In growth experiments with $A$. aurita ephyrae fed different species and concentrations of prey organisms (Artemia sp., Balanus sp., Brachionus sp., Rathkea octopunctata), the specific growth rate increased with increasing prey concentration, and a maximum specific growth rate of about $0.22 \mathrm{~d}^{-1}$ was obtained. For A. aurita medusae fed Acartia tonsa and Artemia sp., maximum growth was about $0.08 \mathrm{~d}^{-1}$. The minimum prey concentration resulting in maximum growth rate was 80 to $100 \mathrm{\mu g} \mathrm{Cl}^{-1}$ for ephyrae (depending on prey type), and about $100 \mathrm{\mu g} \mathrm{C}^{-1}$ for medusae. For $S$. tubulosa fed different prey concentrations of $A$. tonsa nauplii, the maximum specific growth rates were 0.32 and $0.1 \mathrm{~d}^{-1}$ for 2 and $4 \mathrm{~mm}$ individuals, respectively, achieved at prey concentrations between 15 and $30 \mu \mathrm{g} \mathrm{Cl}^{-1}$. Maximum growth rates decreased with initial size in $A$. aurita and A. vitrina, to become approximately constant at 0.05 to $0.06 \mathrm{~d}^{-1}$. Clearance rates $\left(F, \mathrm{~d} \mathrm{~d}^{-1}\right)$ of $A$. aurita offered different prey types increased as a function of the umbrella diameter $(D, \mathrm{~mm})$ squared, expressed as $F=a D^{2}$, where $a$-value depends on prey type. Both maximum specific growth rate and clearance rate increased exponentially with temperature between 4 and $19^{\circ} \mathrm{C}$ for ephyrae, and between 8 and $19^{\circ} \mathrm{C}$ for medusae, but at higher temperatures both growth and clearance decreased markedly. From experiments with A. aurita (both ephyra and medusae) in which growth, ingestion and respiration were measured simultaneously, carbon budgets were constructed for individuals growing at maximum rates when feeding on different prey types. Assimilation efficiency, net growth efficiency, and minimum concentrations of prey organisms needed for sustaining maximum growth were estimated, allowing evaluation of the degree to which jellyfish realize their growth potential in the field, or whether the jellyfish are controlling the zooplankton.
\end{abstract}

KEY WORDS: Clearance rate $\cdot$ Growth of jellyfish - Effect of temperature Carbon budget . Bioenergetics $\cdot$ Aurelia aurita $\cdot$ Sarsia tubulosa $\cdot$ Aequorea vitrina

\section{INTRODUCTION}

During recent decades, there has been a growing scientific interest in the trophic role of jellyfish in the marine pelagic food web (Möller 1980, Båmstedt 1990, Purcell \& Grover 1990, Olesen 1995, Hansson et al. 2005). Locally high densities of jellyfish frequently exert a severe predation impact, and thus control both the abundance of zooplankton and fish larvae (Möller 1984, Schneider \& Behrends 1994, Olesen 1995, Purcell 1997).
A few studies have evaluated the role of the common jellyfish Aurelia aurita in the field by estimating food requirements from energy budgets (Schneider 1989, Olesen et al. 1994, Uye \& Shimauchi 2005). However, complete understanding of energy flux through the food web demands detailed knowledge of the bioenergetics of the organisms. Because both ingestion and respiration may vary strongly with prey type and prey concentration (Hansson et al. 2005, Møller \& Riisgård 2007a), it is important that all parameters in the energy budget are determined at the same time and under the same condi- 
tions (temperature, prey species and concentrations). This was realized by Olesen et al. (1994) who constructed an energy budget for $A$. aurita ephyrae based on simultaneous measurements of actual growth, respiration and food ingestion. But, obviously, more knowledge about the bioenergetics of jellyfish is needed.

To evaluate whether a jellyfish population is food limited, or realizing its growth potential in the field, it is important to know both the potential maximum specific growth rate and the minimum prey concentration at which the maximum growth is achieved. Further, apart from constructing actual energy budgets, it is important to gain more knowledge on how different factors, such as individual size, food availability and temperature, which are fluctuating in the field, affect the different energetic parameters of the budget.

The present study deals with bioenergetics in the scyphomedusa Aurelia aurita and 2 hydromedusae Sarsia tubulosa and Aequorea vitrina. Both A. aurita and S. tubulosa are neritic species (Russell 1953, Kramp 1961) and are common world-wide. In Limfjorden (Denmark), S. tubulosa is present in the plankton during early spring together with $A$. aurita ephyrae. During summer, medusae of $A$. aurita make up the vast majority of the plankton (Hansson et al. 2005, Møller \& Riisgård 2007b, this volume). Before 2004, the hydromedusa $A$. vitrina was unknown in Limfjorden, where it later became very abundant during August and September (Møller \& Riisgård 2007b).

The aim of the present study was to provide data for assessing feeding and growth of Aurelia aurita, Sarsia tubulosa and Aequorea vitrina. This was done by examining the effects of temperature, medusa size, prey concentration and prey species on feeding and growth, and by constructing carbon budgets with data obtained in controlled laboratory experiments where feeding, growth and respiration were measured simultaneously. Such data can be used to evaluate the degree to which the jellyfish realize their growth potential in the field, and to evaluate whether they are controlling the zooplankton. Thus, in a companion paper we use the maximum growth rates obtained in the present work to evaluate whether the jellyfish realize their growth potential in Limfjorden. Further, we use the present data on minimum concentrations of prey organisms needed for sustaining maximum growth for comparison with the actual prey concentrations in Limfjorden to evaluate jellyfish-predation impact (Møller \& Riisgård 2007b).

\section{MATERIALS AND METHODS}

Collection and storage. Medusae were collected in Kertinge Nor (14 to $22 \mathrm{psu}$ ), a shallow cove in the northern part of Fyn, Denmark, and in Skive Fjord (25 psu), an inner branch of Limfjorden in the northern part of Jutland, Denmark. Adult Aurelia aurita specimens were collected in Kertinge Nor during the summer of 2004 and 2005; Aequorea vitrina specimens were collected in Skive Fjord in August 2004. A. aurita ephyrae and Sarsia tubulosa individuals were collected at both sites during the spring of 2004 and 2005. The medusae were brought to the laboratory and kept in aquaria $\left(15^{\circ} \mathrm{C}, 20 \mathrm{psu}\right)$ until experiments could be performed. When stored for more than a few days, the jellyfish were fed Artemia sp. nauplii.

Feeding and growth experiments. Experiments were done with scyphozoan Aurelia aurita (ephyrae and medusae) and the hydrozoans Sarsia tubulosa and Aequorea vitrina. The diameters (A. aurita, A. vitrina) or heights ( $S$. tubulosa) of the medusae were measured before the jellyfish were transferred to aquaria with a known volume of filtered seawater. The jellyfish were offered different types of prey organisms in different concentrations (Table 1). The prey organisms (except Rathkea octopunctata) were raised in monospecific culture. Prey organisms were counted in sub-samples, and aquaria with suspensions of known prey concentrations were prepared for feeding experiments. Once a day, the medusae were transferred to an aquarium with fresh seawater containing an initial prey concentration equal to that used on the previous day. The remaining prey organisms in the old water were retained on a $80 \mu \mathrm{m}$ filter and counted to estimate the total number of prey organisms ingested by the jellyfish during the feeding period. At the end of the experimental period, the sizes of the jellyfish were measured again so that the diameter/height of the experimental animals could be converted to body dry weight. For $A$. aurita medusae and $A$. vitrina individuals, the correlation between medusa diameter $(D, \mathrm{~mm})$ and dry weight $(W, \mathrm{mg})$ was made by calculating the regression equation using pre-measured medusae dried at $60^{\circ} \mathrm{C}$ for $24 \mathrm{~h}$. For ephyrae and $S$. tubulosa specimens, correlations were obtained from the literature.

The specific growth rate $\left(\mu, \mathrm{d}^{-1}\right)$ was determined as: $\mu=\ln \left(W_{t} / W_{0}\right) / t$, where $W_{0}$ and $W_{t}$ are the body dry weights on Day 0 and Day $t$, respectively. The mean prey concentration $\left(C_{m}\right)$, ingestion rate $(I)$ and clearance rate $(F)$ were calculated by the following equations (Olesen et al. 1994): $C_{m}=\exp \left[\ln \left(C_{0} \times C_{t}\right) / 2\right] ; F=$ $V /(t \times n) \times \ln \left(C_{0} / C_{t}\right) ; I=\left(C_{t}-C_{0}\right) /(n \times t)$, or $I=F \times C_{m}$, where $C_{0}$ and $C_{t}=$ prey concentration on Day 0 and Day $t$, respectively, $n=$ number of animals, and $V=$ volume of water in the aquarium. Control experiments were made with aquaria containing prey organisms, but no jellyfish. Unless otherwise indicated, the temperature in all experiments was $15^{\circ} \mathrm{C}$. The experimental conditions are outlined in Table 1. 
Table 1. Aurelia aurita, Sarsia tubulosa, and Aequorea vitrina. Experimental conditions for growth and feeding experiments. Prey type: B: Brachionus sp., Ar: Artemia sp. (1 or 3 d old), Ci: cirriped larvae (Balanus sp., nauplii/cypris), Co: copepods (Acartia tonsa), N: nauplii (Acartia tonsa); R: Rathkea octopunctata. C: approximate concentration. ExperimentGF: growth and feeding; TE: temperature effect; F: feeding. $V$ : incubation volume; $t$ : incubation time; $n$ : number of medusae

\begin{tabular}{|lcccccc|}
\hline Species & Prey & $\begin{array}{c}C \\
\text { (ind. } \mathrm{l}^{-1} \text { ) }\end{array}$ & Experiment & $\begin{array}{c}V \\
\text { (l) }\end{array}$ & $\begin{array}{c}t \\
\text { (d) }\end{array}$ & $n$ \\
\hline A. aurita & $\mathrm{Ar}(1 \mathrm{~d})$ & $30-100$ & $\mathrm{GF}$ & 4 & 4 & 6 \\
(ephyrae) & $\mathrm{B}$ & $40-600$ & $\mathrm{GF}$ & 4 & 4 & 8 \\
& $\mathrm{~B}$ & $\sim 800$ & $\mathrm{TE}$ & $1-5$ & 3 & 5 \\
& $\mathrm{Co}$ & $25-200$ & $\mathrm{GF}$ & 4 & 4 & 8 \\
& $\mathrm{Ci}$ & $10-50$ & $\mathrm{GF}$ & 4 & 4 & 8 \\
& $\mathrm{R}$ & $2-5$ & $\mathrm{GF}$ & 3 & 3 & 5 \\
A. aurita & $\mathrm{Ar}(1 \mathrm{~d})$ & $30-100$ & $\mathrm{GF}$ & $30-60$ & 4 & 5 \\
(medusae) & $\mathrm{Ar}(1 \mathrm{~d})$ & $\sim 90$ & $\mathrm{TE}$ & $30-60$ & 3 & 5 \\
& $\mathrm{Ar}(3 \mathrm{~d})$ & $\sim 50$ & $\mathrm{~F}$ & $30-60$ & 1 & 4 \\
S. tubulosa & $\mathrm{Co}$ & $5-110$ & $\mathrm{GF}$ & $70-85$ & 3 & 5 \\
A. vitrina & $\mathrm{N}$ & $30-500$ & $\mathrm{GF}$ & $2-4$ & 4 & 7 \\
& $\mathrm{Co}$ & $\geq 90$ & $\mathrm{GF}$ & $15-30$ & 4 & 5 \\
& & F & 5 & 1 & 5 \\
\hline
\end{tabular}

$5 \mathrm{~mm}$ ) were fed Brachionus sp., and temperature effect was measured between 4 and $26^{\circ} \mathrm{C}$ and between 4 and $23^{\circ} \mathrm{C}$ in clearance and growth experiments, respectively. For medusae $(D=39.9 \pm 0.9 \mathrm{~mm})$ fed Artemia sp., the acute temperature effect was measured between 8 and $23^{\circ} \mathrm{C}$.

Respiration $(\boldsymbol{R})$. Respiration rate was measured at the end of the growth experiments when the medusae were growing at maximum specific growth rates. Respiration, measured as oxygen consumption, was recorded by means of an oxygen electrode (CellOx 325 [WTW]) connected to an oxygen measuring instrument (Oxi 197i [WTW]). The electrode was placed in a flow-through chamber connected by tubes to a respiration chamber holding the animals. Aerated filtered seawater was pumped through the chambers with a peristaltic pump. Measurements were started by closing the system so that the water was recirculated through the respiration chamber past the electrode and back

Aurelia aurita: Feeding experiments with ephyra ( $D=3.5$ to $7 \mathrm{~mm}$ ) were carried out using Artemia sp. (1 d old), adult Acartia tonsa, Brachionus sp., Balanus sp. nauplii/cypris, and Rathkea octopunctata as prey organisms offered at different concentrations. Feeding experiments with medusae were carried out with individuals of known umbrella diameter $(D=45 \mathrm{~mm})$ offered Artemia sp. (1 d old), or Acartia tonsa (copepodites/adults) as prey in different concentrations. To estimate the maximum specific growth rate as a function of initial body size, experiments were carried out with medusae of different initial umbrella diameter ( $D_{0}=5$ to $650 \mathrm{~mm}$ ) fed Artemia sp. (1 d old) or A. tonsa in surplus. In addition, clearance experiments were performed with different sizes of medusae offered Artemia sp. (3 d old).

Sarsia tubulosa: Experiments were performed on 2 sizes of medusae $(D=2.3 \pm 0.04$, and $4.2 \pm 0.1 \mathrm{~mm})$ offered newly hatched Acartia tonsa nauplii in different concentrations.

Aequorea vitrina: Maximum specific growth rate as a function of umbrella diameter was measured using medusae with different initial bell diameters $(D=6$ to $50 \mathrm{~mm}$ ) fed Artemia sp. (1 d old) in surplus. In addition, 3 clearance experiments were done with medusae of known body dry weights $(W=3.3 \pm 0.2 \mathrm{mg}$ ) offered adult Acartia tonsa as prey.

Temperature effect. Effects of temperature on clearance rate and maximum specific growth rate were measured for Aurelia aurita ephyrae and medusae (Table 1). The temperature was controlled by means of a thermostatic water bath. Ephyrae $(D \approx$ again. Each measurement was followed by a control measurement without jellyfish. The experiments were run for no longer than $45 \mathrm{~min}$, and the oxygen saturation of the water never fell below $80 \%$. All measurements were made at $15^{\circ} \mathrm{C}$, unless otherwise noted. The volumes of respiration chambers used varied from 25 to $400 \mathrm{ml}$, and the number of individuals varied between 5 and 15. The flow rate in the system was $5 \mathrm{ml}$ $\mathrm{min}^{-1}$. The electrode was calibrated in an OxiCal-SL air calibration vessel.

The oxygen concentration was plotted as a function of time, and expressed by a linear regression line. The respiration rate was calculated as $R=b \times V / n$, where $b$ is the slope of the regression line, $V=$ volume of water in the respiration vessel and tubes (l), and $n=$ number of animals. The oxygen consumption in the control was subtracted from $R$ to obtain the respiration rate of the jellyfish.

Bioenergetics. The energy (or carbon) budget of a jellyfish can be expressed as $P=I-R-E=A-R$, where $P=$ production, $I=$ ingestion, $R=$ respiration, $E=$ excretion (faeces and urine), and $A=$ assimilated food. The budget can also be written as $P=(F \times C \times$ $A E$ ) $-R$, where $F=$ clearance rate, $C=$ prey concentration, and $A E=$ assimilation efficiency. The following definitions are used in the present study: minimum prey concentration resulting in maximum jellyfish growth, $C_{\min }=\left(G_{\max }+R\right) /(F \times A E)$, where $G_{\max }=$ maximum growth rate $=\mu_{\max } \times W, \mu_{\max }=$ maximum specific growth rate, and $W=$ medusa body mass; assimilation efficiency, $A E=(G+R) / I$; and net growth efficiency, $\mathrm{NGE}=G / A=G /(G+R)$. 
Conversion factors. The following equations were used to estimate dry weight ( $W, \mathrm{mg})$ from umbrella diameter $(D, \mathrm{~mm})$ in Aurelia aurita: ephyrae: $W=1.913$ $\times 10^{-3} D^{2.998}$ (Båmstedt et al. 1999); medusae $(\geq 20 \mathrm{~mm})$ : $W=0.004 D^{2.7}$ (present study); and in Aequorea vitrina: $W=0.03 D^{2.3}$ (present study). For Sarsia tubulosa the bell height $(H, \mathrm{~mm})$ was converted to carbon content $\left(W_{\mathrm{C}}, \mu \mathrm{g}\right.$ C): $W_{\mathrm{C}}=0.443 H^{3.10}($ Daan 1986); $1 \mathrm{mg}$ dry weight (Sarsia sp.) $=3.5 \mathrm{~J}=67 \mu \mathrm{g} \mathrm{C}$ (Schneider 1988, Matsakis \& Conover 1991); $1 \mathrm{mg}$ dry weight (ephyra) = $3.66 \mathrm{~J}=70 \mu \mathrm{g} \mathrm{C} ; 1 \mathrm{mg}$ dry weight (medusae) $=2.24 \mathrm{~J}=$ $50 \mu \mathrm{gC}$ (Schneider 1988); $1 \mu \mathrm{l} \mathrm{O}{ }_{2}=0.46 \mu \mathrm{gC}$ (Uye \& Shimauchi 2005), 1 Brachionus plicatilis $=0.15 \mu \mathrm{gC}$ (Szyper 1989), 1 Artemia sp. $=1.16 \mu g$ C (Szyper 1989); 1 Acartia tonsa (copepodite/adult, $680 \mu \mathrm{m})=2.1 \mu \mathrm{g} \mathrm{C}$ (Berggreen et al. 1988), 1 A. tonsa nauplius $(280 \mu \mathrm{m})=$ $0.15 \mu \mathrm{g} \mathrm{C}$ (Berggreen et al. 1988); 1 Balanus sp. (nauplius/cypris) $=2.46 \mu \mathrm{g} \mathrm{C}$ (Möller 1979, Muxagata et al. 2004), 1 Rathkea octopunctata $=5 \mu \mathrm{gC}$ (Matsakis \& Conover 1991).

\section{RESULTS}

Fig. 1 shows the relationship between initial medusa sizes and maximum specific growth rates of Aurelia aurita and Aequorea vitrina fed Artemia and/or Acartia tonsa in surplus. The maximum specific growth rate declined with increasing initial medusa size to become approximately constant at 6 and $5 \% \mathrm{~d}^{-1}$ for A. aurita and $A$. vitrina, respectively.

Results from experiments carried out on 2 size groups of Sarsia tubulosa fed different prey concentrations of Acartia tonsa nauplii are depicted in Fig. 2. The maximum specific growth rates were 32 and $10 \% \mathrm{~d}^{-1}$ for $2.3 \pm 0.04$ and $4.2 \pm 0.1 \mathrm{~mm}$ individuals, respectively The maximum specific growth rate was achieved at a prey concentration between 15 and $30 \mu \mathrm{C} \mathrm{l}^{-1}$, corresponding to 80 and 150 nauplii $\mathrm{l}^{-1}$ (Fig. 2A). In the above growth experiments, clearance rate and ingestion rate were also measured (Fig. 2B,C). The clearance rates were approximately constant at all prey concentrations, and consequently, the ingestion rate increased linearly with prey concentration in the observed interval.

Results from growth experiments with Aurelia aurita ephyrae fed different prey concentrations and prey species are shown in Fig. 3. The specific growth rate increased with increasing prey concentration, and a maximum specific growth rate of about $22 \% \mathrm{~d}^{-1}$ was obtained between 80 and $100 \mathrm{\mu g} \mathrm{C} \mathrm{l}^{-1}$, corresponding

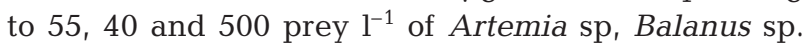
and Brachionus sp., respectively. With Rathkea octopunctata as prey, maximum growth rate was not obtained, due to insufficient prey availability. When

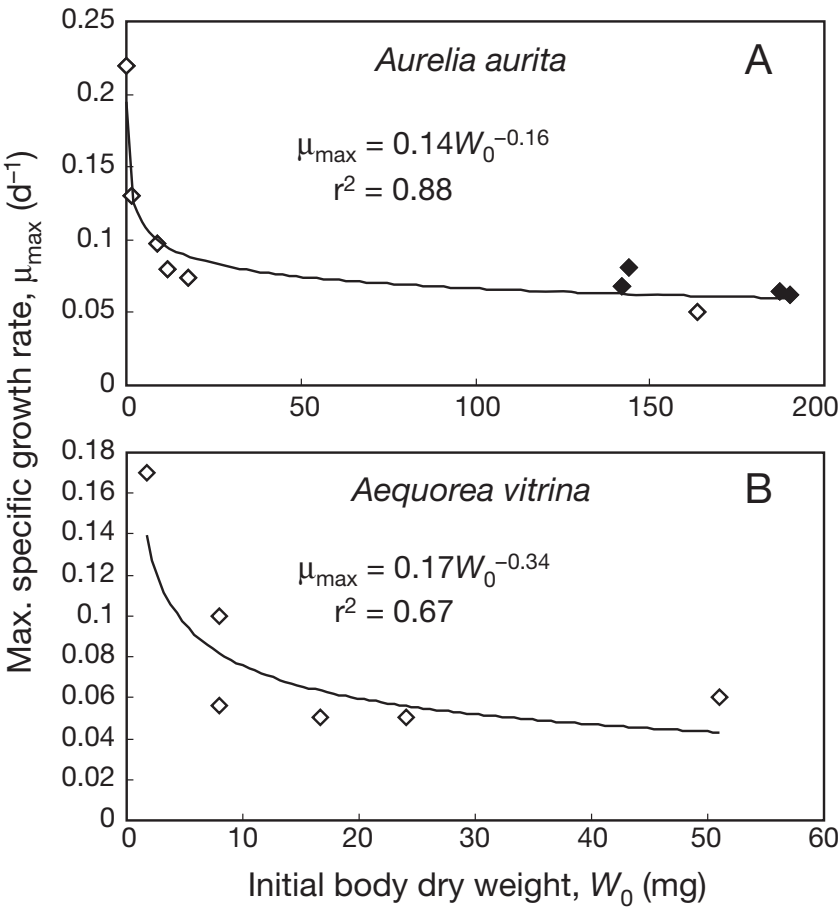

Fig. 1. Maximum specific growth rate as a function of initial dry weight for (A) Aurelia aurita and (B) Aequorea vitrina fed Artemia sp. $(\diamond)$ and Acartia tonsa $(\diamond)$ in surplus. Regression lines and their equations are shown

adult Acartia tonsa was used as prey, the specific growth rates remained relatively low $(-2,13$ and $6 \%$ $\left.\mathrm{d}^{-1}\right)$, although the concentrations of prey offered were high $\left(25,100\right.$ and 190 copepods $\left.\mathrm{l}^{-1}\right)$. The clearance rate was approximately constant at all prey concentrations used, and consequently the ingestion rate increased linearly with prey concentration in the observed interval for all prey species (not shown). The average clearance rates for the different prey types are given in Table 2.

Fig. 4 shows specific growth rates as a function of prey concentration for Aurelia aurita medusae when preying on Acartia tonsa (copepodites/adults) and Artemia sp. $\mu_{\max }$ was about $8 \% \mathrm{~d}^{-1}$, obtained at a prey concentration of about $100 \mu \mathrm{g} \mathrm{Cl}^{-1}$. For both prey species, the clearance rate was nearly identical at all prey concentrations (not shown), thus indicating that the ingestion rate must have increased linearly with prey concentration.

Fig. 5 shows the clearance rate as a function of umbrella diameter of Aurelia aurita offered Acartia tonsa and Artemia sp. as prey. Clearance increased as a function of the diameter squared $\left(\mathrm{F}=a D^{2}\right)$, but the $a$-values varied, indicating that clearance rate depended on prey type. Clearance rates $\left(F, l d^{-1}\right)$ of the different prey can also be expressed as a function of medusa dry weight $(W, \mathrm{mg})$, resulting in linear 

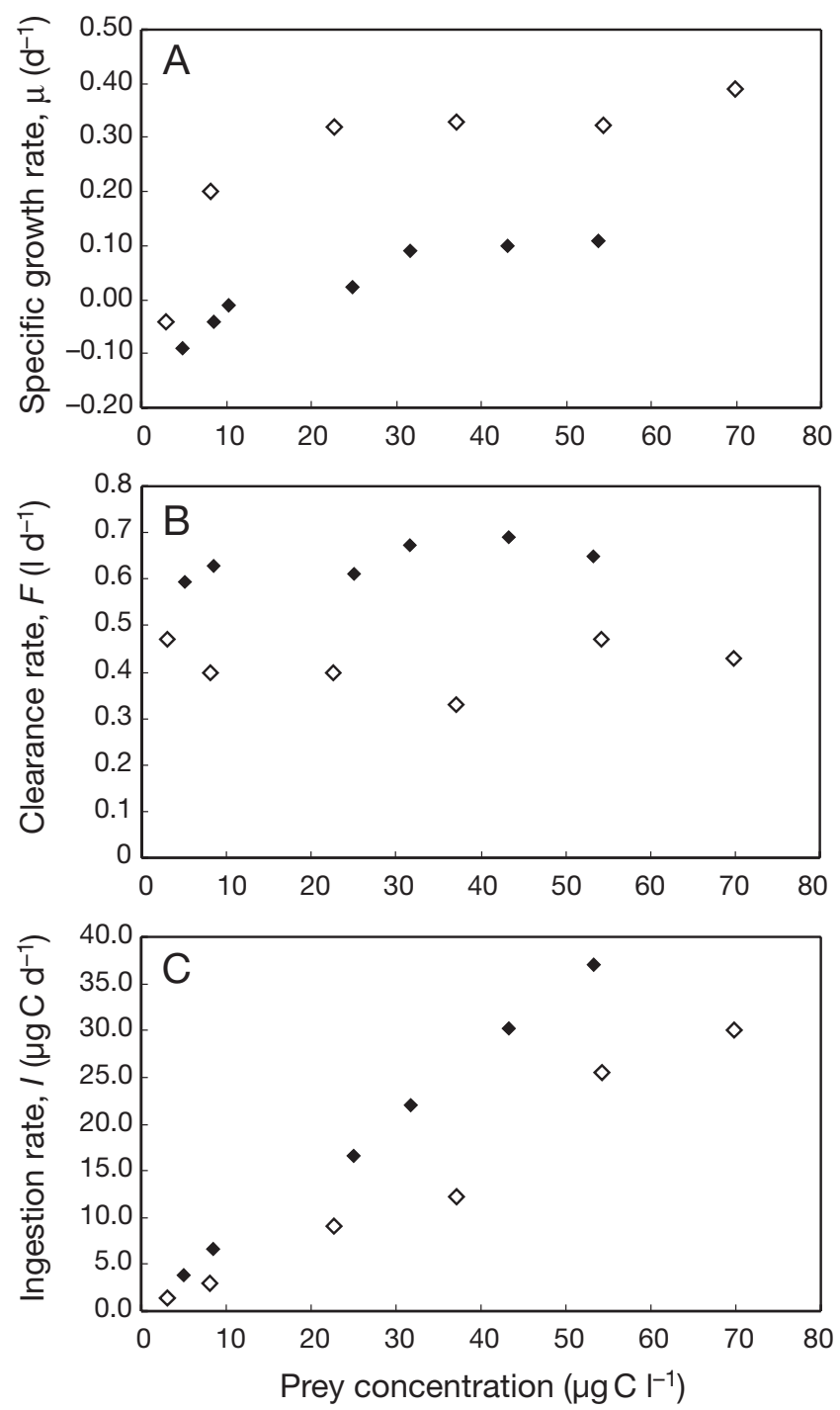

Fig. 2. Sarsia tubulosa. (A) Specific growth rate, (B) clearance rate, and $(C)$ ingestion rate as a function of prey concentration for 2 size groups of medusae preying on Acartia tonsa nauplii.

Umbrella height: $\diamond: 2.3 \pm 0.04 \mathrm{~mm}_{i} \diamond: 4.2 \pm 0.1 \mathrm{~mm}$

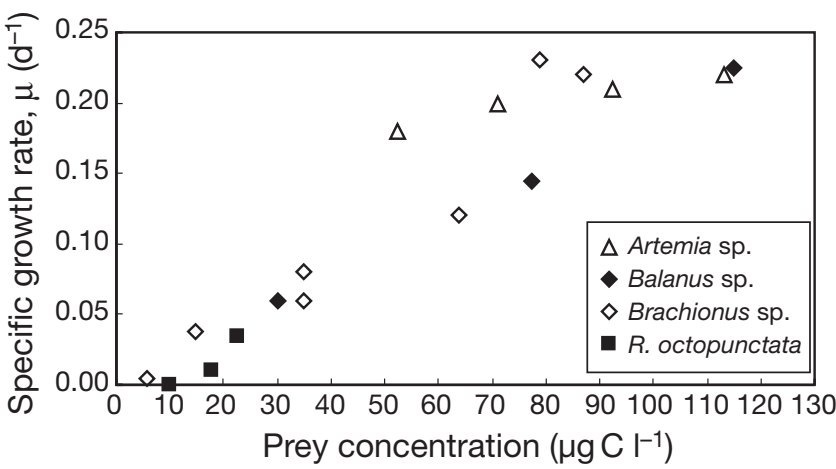

Fig. 3. Aurelia aurita. Specific growth rate of ephyrae as a function of concentration of different prey types (Artemia sp. cirripeds, rotifers, Rathkea octopunctata)
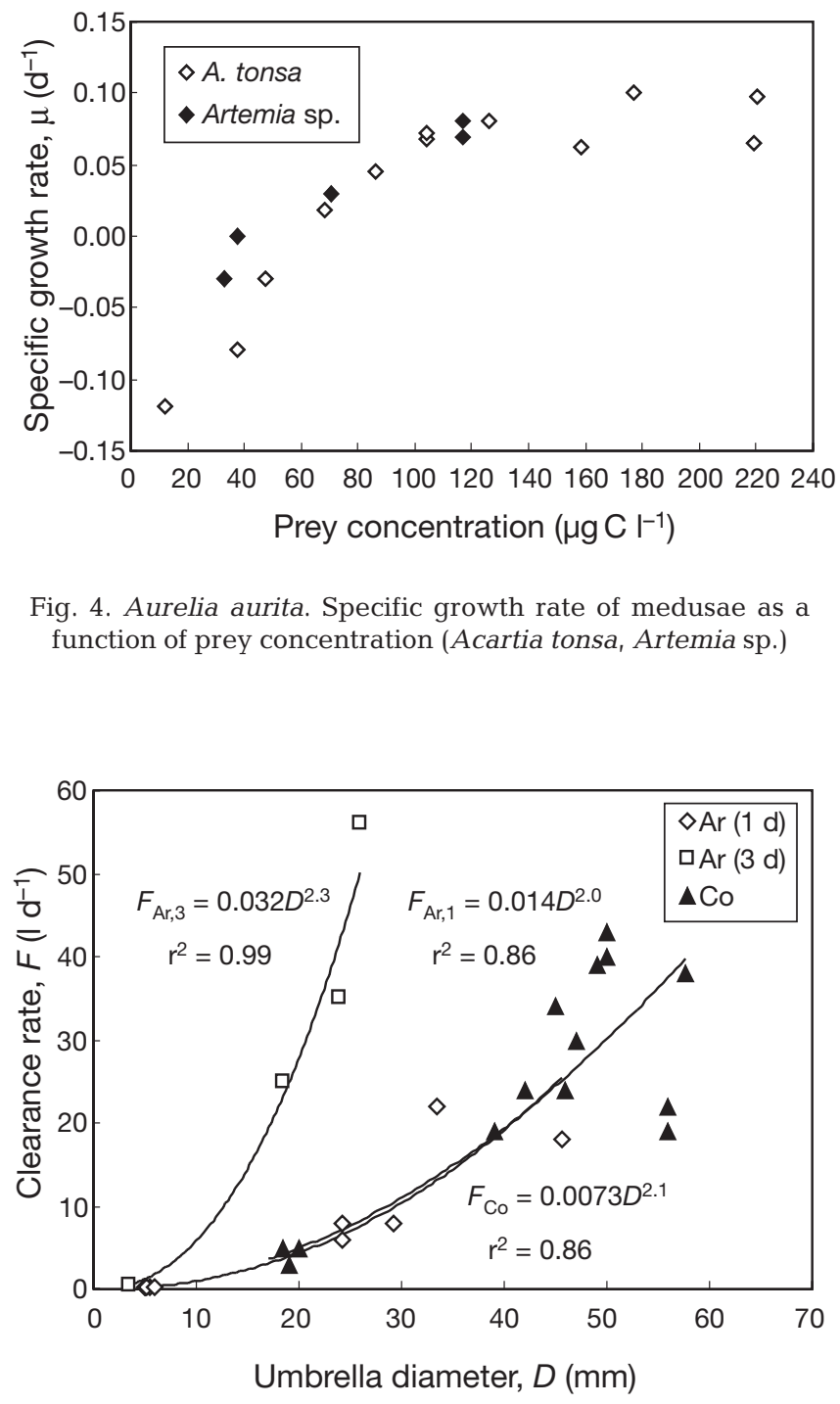

Table 2. Aurelia aurita. Clearance rate $(F)$ of ephyrae for different size groups $(W)$ during growth experiments with different prey types. B: Brachionus sp., Ar: Artemia sp., $\mathrm{Ci}$ : cirriped larvae (Balanus sp., nauplii/cypris), Co: copepods (Acartia tonsa); R: Rathkea octopunctata. Values are mean $\pm \mathrm{SD}$

\begin{tabular}{|lcc|}
\hline Prey & $\begin{array}{c}W \\
(\mathrm{mg} \text { dry wt })\end{array}$ & $\begin{array}{c}F \\
\left(\mathrm{l} \mathrm{d}^{-1}\right)\end{array}$ \\
\hline $\mathrm{Ar}$ & $0.27 \pm 0.06$ & $0.26 \pm 0.03$ \\
$\mathrm{Ci}$ & $0.50 \pm 0.08$ & $0.45 \pm 0.05$ \\
$\mathrm{~B}$ & $0.25 \pm 0.03$ & $0.54 \pm 0.08$ \\
$\mathrm{R}$ & $0.17 \pm 0.02$ & $0.21 \pm 0.05$ \\
$\mathrm{Co}$ & $0.10 \pm 0.02$ & $0.15 \pm 0.11$ \\
\hline
\end{tabular}

Fig. 4. Aurelia aurita. Specific growth rate of medusae as a function of prey concentration (Acartia tonsa, Artemia sp.)

Fig. 5. Aurelia aurita. Clearance rate $(F)$ as a function of umbrella diameter when preying on Acartia tonsa (Co), and on $1 \mathrm{~d}(\mathrm{Ar}, 1)$ and $3 \mathrm{~d}(\mathrm{Ar}, 3)$ old Artemia sp. Regression lines and their equations are shown 
relationships in a $\log$-log plot, and subsequently expressed as: $F_{\mathrm{Ar}, 1}=0.70 W^{0.74}, F_{\mathrm{Ar}, 3}=3.9 W^{0.78}$, and $F_{\text {Co }}=0.76 W^{0.73}$.

Clearance $\left(F, 1 \mathrm{~d}^{-1}\right)$ as a function of dry weight $(W$, mg) of Aequorea vitrina preying on Artemia sp. could be expressed as a linear relationship in a log-log plot with the equation: $F=0.45 W^{0.91} ; \mathrm{r}^{2}=0.93(\mathrm{n}=4)$. The clearance rate of $A$. vitrina preying on copepods was $0.3 \mathrm{l} \mathrm{d}^{-1}$ for a $3.3 \pm 0.2 \mathrm{mg}$ dry wt individual.

The effect of temperature on maximum specific growth rates and clearance rates of Aurelia aurita ephyrae and medusae is shown in Fig. 6. Both maximum specific growth rate and clearance rate increased exponentially with temperature between 4 and $19^{\circ} \mathrm{C}$ for ephyrae, and between 8 and $19^{\circ} \mathrm{C}$ for medusae, but at higher temperatures both growth and clearance rates decreased markedly.

From experiments performed with Aurelia aurita (both ephyrae and medusae) in which growth $(G)$, ingestion $(I)$ and respiration $(R)$ were measured simultaneously, carbon budgets were constructed for individuals growing at maximum rates when consuming different prey types (Table 3). The values shown for $I$, $R$ and $G_{\max }$ are measured values, whereas $A E$, NGE and $C_{\min }$ were estimated on basis of these values. For $A$. aurita ephyrae, the values from experiments with different prey types were similar. In general, $A E$ was 64 to $74 \%$, and NGE was 20 to $28 \%$. However, in experiments where copepods were offered as prey organisms, the values were considerably lower, $A E$ and NGE being 13 and $16 \%$, respectively. For adult A. aurita, the values differed little between experiments with different prey types, and $A E$ and NGE were 33 to 37 and 25 to $33 \%$, respectively. $A E$ tended to increase at lower prey concentrations (not shown). The minimum prey concentration resulting in maximum specific growth rate of medusae $\left(C_{\min }\right)$ was calculated to be 79.1 to $114.5 \mu \mathrm{g} \mathrm{C} \mathrm{l}^{-1}$ for ephyrae (depending on prey type) and 111.2 to $118.3 \mu \mathrm{g} \mathrm{C}^{-1}$ for medusae (Table 3).
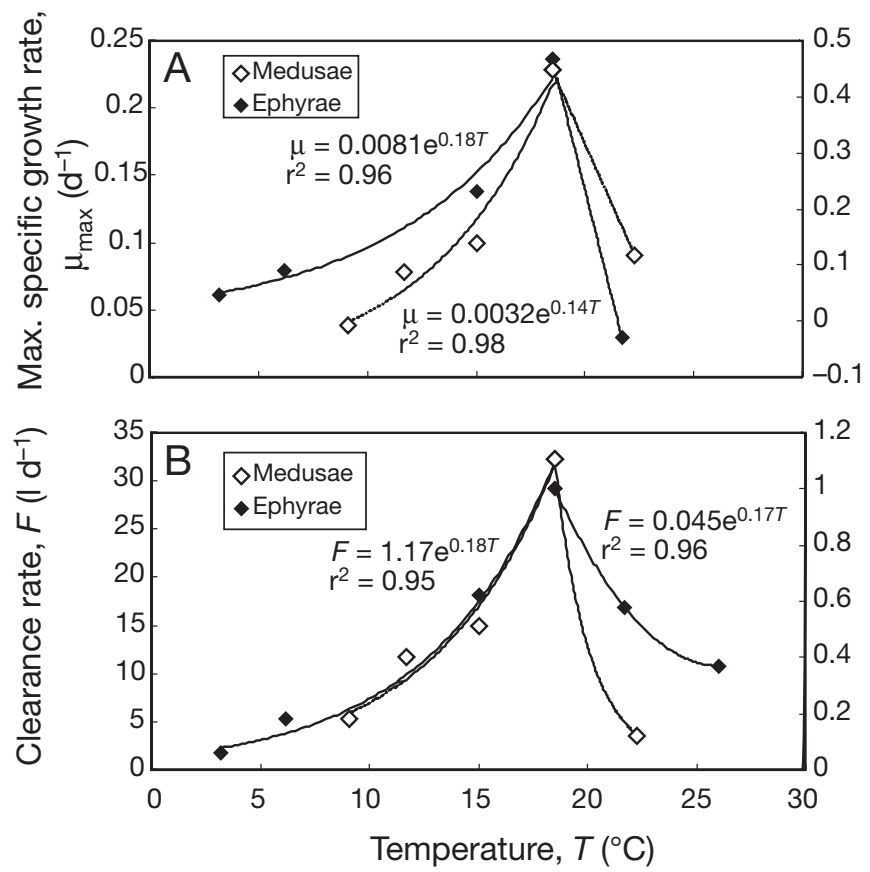

Fig. 6. Aurelia aurita. Effect of temperature on (A) maximum specific growth rate, and (B) clearance rate, of ephyrae (right $y$-axis) and medusae (left $y$-axis). Regression lines and their equations are shown

The net growth efficiency was found to increase with specific growth rate, becoming constant when maximum growth rate was achieved; cf. Fig. 7, which shows an example with ephyrae preying on Brachionus sp.

\section{DISCUSSION}

\section{Growth}

There have been several studies on growth rates in Aurelia aurita ephyrae. Generally, the maximum specific growth rate is about $24 \% \mathrm{~d}^{-1}$ at $15^{\circ} \mathrm{C}$, obtained

Table 3. Aurelia aurita. Bioenergetic parameters for medusae fed with different prey types and growing at maximum specific growth rate. B: Brachionus sp., Ar: Artemia sp., Ci: cirriped larvae, Co: copepods (Acartia tonsa). $W_{\mathrm{C}}$ : medusa carbon content; $\mu_{\max }$ : maximum specific growth rate; $C$ : prey concentration; $I$ : ingestion rate; $R$ : respiration; $G_{\max }:$ growth rate $=\mu_{\max } W_{C i} A E$ : as-

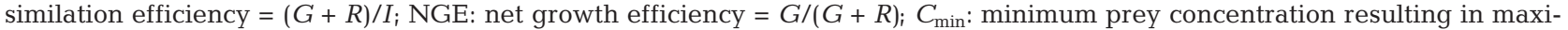
mum

\begin{tabular}{|lcccccccccc|}
\hline Stage & Prey & $\begin{array}{c}W_{\mathrm{C}} \\
(\mu \mathrm{g} \mathrm{C})\end{array}$ & $\begin{array}{c}\mu_{\max } \\
\left(\mathrm{d}^{-1}\right)\end{array}$ & $\begin{array}{c}C \\
\left(\mu \mathrm{C}^{-1}\right)\end{array}$ & $\begin{array}{c}I \\
\left(\mu \mathrm{C} \mathrm{d}^{-1}\right)\end{array}$ & $\begin{array}{c}R \\
\left(\mu \mathrm{C} \mathrm{d}^{-1}\right)\end{array}$ & $\begin{array}{c}G_{\max } \\
\left(\mu \mathrm{C} \mathrm{d} \mathrm{d}^{-1}\right)\end{array}$ & $\begin{array}{c}A E \\
(\%)\end{array}$ & $\begin{array}{c}\mathrm{NGE} \\
(\%)\end{array}$ & $\begin{array}{c}C_{\min } \\
\left(\mu g \mathrm{C}^{-1}\right)\end{array}$ \\
\hline Ephyra & $\mathrm{B}$ & 17.5 & 0.23 & 78.8 & 31.5 & 16.2 & 4.0 & 64.3 & 19.9 & 79.1 \\
Ephyra & $\mathrm{Ar}$ & 16.8 & 0.22 & 92.8 & 20.2 & 9.6 & 3.7 & 66.5 & 27.8 & 80.6 \\
Ephyra & $\mathrm{Ci}$ & 38.5 & 0.23 & 115.0 & 44.5 & 24.4 & 8.7 & 74.3 & 26.2 & 114.5 \\
Ephyra & $\mathrm{Co}$ & 6.3 & 0.13 & 98.0 & 40.6 & 4.5 & 0.8 & 13.0 & 15.5 & - \\
Medusa & $\mathrm{Co}$ & 8150.0 & 0.08 & 107.6 & 3370.4 & 607.3 & 652.0 & 37.4 & 33.1 & 118.3 \\
Medusa & $\mathrm{Ar}$ & 4800.0 & 0.08 & 116.0 & 2378.0 & 523.7 & 384.0 & 32.6 & 25.2 & 111.2 \\
\hline
\end{tabular}




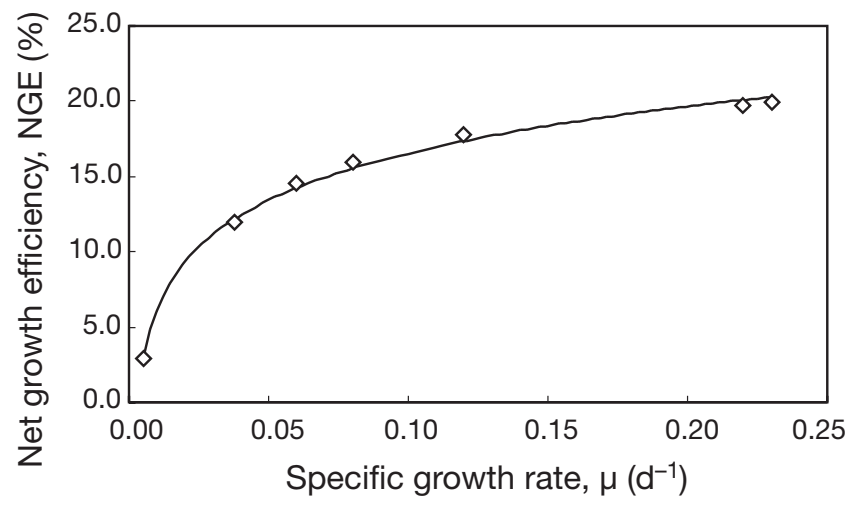

Fig. 7. Aurelia aurita. Net growth efficiency as a function of specific growth rate of ephyrae preying on Brachionus sp.

with different prey species, e.g. Artemia sp. (Båmstedt et al. 1999, 2001) and Brachionus sp. (Olesen et al. 1994, Frandsen \& Riisgård 1997). In the present study, maximum specific growth rates of 22 to $24 \% \mathrm{~d}^{-1}$ were obtained with Brachionus sp., Artemia sp. and Balanus sp. as prey at minimum concentrations $\left(C_{\min }\right)$ of 80 to $100 \mu \mathrm{g} \mathrm{C}^{-1}$, depending on prey type (Fig. 3). Olesen et al. (1994) found $C_{\min }$ to be about $60 \mu \mathrm{g} \mathrm{C} \mathrm{l}^{-1}$ when preying on Brachionus sp. Båmstedt et al. (2001) studied the effect of several diets on the growth of newly released $A$. aurita ephyrae and found that they did not grow well (4 to $9 \% \mathrm{~d}^{-1}$ ) when offered adult copepods (Calanus finmarchicus). Båmstedt et al. (op. cit.) argued that this might be due to the nutritional quality of the copepods. This suggestion is supported by the present study, where ephyrae offered copepods (Acartia tonsa) also grew much less than might be expected from the number of prey ingested. With the hydromedusa Rathkea octopunctata as prey, maximum growth rates were not obtained, since not enough prey organisms were available, but the actual growth rates were comparable to those found for other prey species offered at similar carbon concentrations. This is the first study that reports on growth in A. aurita preying on hydromedusae, although several authors have suggested that hydromedusae might be an important food source for ephyrae (Matsakis \& Conover 1991, Sullivan et al. 1994, 1997).

So far, little attention has been given to maximum specific growth rates in larger individuals, and in some studies it has been assumed to be constant with size (Olesen et al. 1994). In the present study, the maximum specific growth rate of Aurelia aurita medusae was about $8 \% \mathrm{~d}^{-1}$, obtained at a prey concentration of about $100 \mu \mathrm{g} \mathrm{C} \mathrm{l}^{-1}$ with adult Acartia tonsa and Artemia sp. as prey (Fig. 4). Results obtained for Sarsia tubulosa showed that 2 and $4 \mathrm{~mm}$ individuals had maximum specific growth rates of 32 and $10 \% \mathrm{~d}^{-1}$, obtained at prey concentrations of 15 and $30 \mu \mathrm{g} \mathrm{C}^{-1}$, respectively (Fig. 2). No previous data exist on $C_{\min }$ for A. aurita medusae and $S$. tubulosa. The present data indicate that maximum specific growth rates in larger medusae may be lower than in smaller stages. A similar indication has been found for $S$. tubulosa offered copepods in surplus (Daan 1986).

Hansson (1997) summarized existing data on specific growth rates in Aurelia aurita obtained in both laboratory and field work. A plot of specific growth rate as a function of medusa size indicated a decreasing tendency, although not all growth rates were maximum values, and they were obtained under different conditions. In the present study, the medusae ( $A$. aurita and A. vitrina) were not food limited to ensure maximum specific growth rates, which were found to decrease from initial values of about 17 to $22 \% \mathrm{~d}^{-1}$, stabilizing at about 5 to $6 \% \mathrm{~d}^{-1}$ (Fig. 1). One of the explanations for this phenomenon may be, for example, the shunting of energy into gametes instead of somatic growth (Hansson 1997). To our knowledge, the only other study reporting maximum specific growth rates in adult $A$. aurita was that of Ishii \& Båmstedt (1998). Individuals of 4 to $12 \mathrm{~cm}$ were offered prey in surplus. When plotting their (op. cit.) growth data as a function of initial medusa dry weight $\left(W_{0}, \mathrm{mg}\right)$, the trend also indicated a decreasing tendency $\left(\mu_{\max }=0.34 W_{0}^{-0.28}\right)$, and the maximum specific growth rate decreased to stabilize at about $5 \% \mathrm{~d}^{-1}$.

Ishii \& Båmstedt (1998) summarized existing data on the relation between size and reproductive maturity in jellyfish, and it appeared that when Aurelia aurita is food limited, it shunts energy into gamete production at an earlier stage. In Horsea Lake, England, A. aurita never gets larger than about $10 \mathrm{~cm}$ in diameter, and it matures at about $2 \mathrm{~cm}$ umbrella diameter. This is also the case in Kertinge Nor, Denmark, where we collected individuals for the present study. In marine areas where the medusae are not food limited, they attain larger maximum bell diameters (up to 30 to $40 \mathrm{~cm}$ ), and they mature at a larger size. This may explain why the maximum specific growth rate declined earlier in individuals from Kertinge Nor (used in the experiments shown in Fig. 1) than in medusae from Horsea Lake (Ishii \& Båmstedt 1998).

The only available data on growth in Aequorea sp. were reported by Arai (1980) who offered A. victoria Artemia nauplii as prey until the hydromedusa was large enough to feed on a mixed diet of the ctenophore Pleurobrachia pileus, Artemia sp. and Phialidium sp. Unfortunately, the concentrations were not reported, but food was always available. Specific growth rates estimated from Arai's (1980) data show a decrease with size (14 to $2 \% \mathrm{~d}^{-1}$ ) within the same size range as that of the present study. 


\section{Feeding}

In the present study, clearance rates were obtained for Aurelia aurita ephyrae feeding on Brachionus sp., Artemia sp., adult Acartia tonsa, Balanus sp. larvae and the hydromedusa Rathkea octopunctata (Table 1). Clearance rate depended on prey type, but all rates were in the range of 150 to $540 \mathrm{ml} \mathrm{d}^{-1}$, which is in agreement with Båmstedt et al. (1994) who found the clearance rate for ephyrae to be in the range of 100 to $800 \mathrm{ml} \mathrm{d}^{-1}$, depending on prey type. Apart from these data, there have been no previous quantitative measurements on ephyrae preying on $A$. tonsa and R. octopunctata.

Size-dependent clearance rate $(F)$ in Aurelia aurita was described by the expression $F=a D^{b}$, with $b$-exponents close to 2 when related to umbrella diameter $(D)$. Clearance related to medusa dry weight $(W)$ was described by the expression $F=a W^{b}$, with $b$-exponents of 0.7 to 0.8 . The $b$-exponents were quite similar in both expressions, but the $a$-values differed depending on prey type. Clearance rates of $1 \mathrm{~d}$ old Artemia sp. and Acartia tonsa were quite similar, whereas the clearance rate of $3 \mathrm{~d}$ old Artemia sp. was about 3 times higher (Fig. 5). The clearance rates obtained with Acartia tonsa as prey are close to those obtained by Olesen (1995) with the same prey type. He found that a $22 \mathrm{~mm}$ individual cleared $6.4 \mathrm{l} \mathrm{d}^{-1}$, which may be compared to $6.0 \mathrm{l} \mathrm{d}^{-1}$ for an individual of the same size in the present study. That clearance rates depend on prey type was also noticed by Hansson et al. (2005), who quantified the clearance rate of $A$. aurita based both on laboratory clearance experiments using different prey organisms and on analysis of gut contents of medusae collected in the field. In general, clearance was approximately scaled to bell diameter squared, but $a$-values were different between prey groups. Clearance decreased in the following order: cladocerans, copepods, copepod nauplii, mussel larvae. Similar results were obtained by Hansson (2006), who estimated clearance of copepods to be about 3 times lower and 5 to 6 times higher than clearance of cladocerans and copepod nauplii, respectively. The present study shows that the clearance rate depends not only on prey type, but also on the stage/age of the prey. Thus, the clearance rate of $A$. aurita obtained with $3 \mathrm{~d}$ old Artemia sp. as prey was 3 times higher than clearance of $1 \mathrm{~d}$ old Artemia (Fig. 5).

Adult copepods and cirriped nauplii are considered to be the primary food source for Sarsia sp., while copepod nauplii seem to be of less importance (Purcell 1989, Costello \& Colin 2002). The present study presents clearance rates of $S$. tubulosa offered copepod nauplii (Fig. 2B), but otherwise only few quantitative measurements exist. Hansson et al. (2005) reported that the clearance rates of a $5.1 \mathrm{~mm} S$. tubulosa offered adult Acartia tonsa as prey was $0.3 \mathrm{l} \mathrm{d}^{-1}\left(11^{\circ} \mathrm{C}\right)$, which may be compared to the present study in which 2 and $4 \mathrm{~mm}$ individuals cleared about 0.4 and $0.5 \mathrm{l} \mathrm{d}^{-1}$, respectively when offered nauplii as prey $\left(15^{\circ} \mathrm{C}\right)$. Recently, Hansson \& Kiørboe (2006) measured clearance in $S$. tubulosa offered adult copepods, cirriped nauplii and larvae as prey, and they found that the clearance rate decreased in this order.

Diet and prey selection of Aequorea victoria and $A$. aequorea have been reported by several authors (Purcell 1989, 1991, Costello \& Colin 2002). The main diet seems to comprise gelatinous zooplankton, ichthyplankton, and to a lesser extent, crustacean prey. Purcell (2003) estimated weight-specific clearance rates from gut contents in $A$. aequorea. The clearance rates have been recalculated for a $3.3 \mathrm{mg}$ dry wt individual for comparison with rates found in this study (Table 4). The present results for copepods/Artemia sp. are in the same range as those for copepods and cladocerans reported by Purcell (2003), but the clearance rate for larvaceans is much higher (up to 30 times higher than for copepods). As suggested by Purcell (2003), Aequorea sp. is presumably specialized for feeding on larger soft-bodied prey, e.g. ctenophores, which are vulnerable to predation by Aequorea sp. (Arai 1986).

Aequorea victoria has been described as a cruisingpredatory medusa (Costello \& Colin 2002, Colin et al. 2003). However, a recent study by Riisgård (2007) revealed that $A$. vitrina is an ambush feeder, usually remaining stationary in the water column with its very long marginal tentacles hanging down motionless, ready for ambush capture of prey organisms. Videomicroscope observations made by Riisgård (2007) revealed that $A$. vitrina is efficient in capturing brine shrimps (Artemia salina), less efficient in capturing rotifers (Brachionus plicatilis), and very inefficient at copepod (Acartia tonsa) capture. This is in agreement with the observations and quantitative measurements in the present study. However, it should be noted that the present clearance rates may be biased because an important prerequisite for using the clearance formula, i.e. efficient mixing of the water in the experimental aquaria, was not fulfilled (because the water was

Table 4. Aequorea sp. Clearance rate $(F)$ measured for a $3.3 \mathrm{mg}$ dry wt individual offered different prey types

\begin{tabular}{|llcl|}
\hline Predator & \multicolumn{1}{c}{ Prey } & $F\left(\mathrm{l} \mathrm{d}^{-1}\right)$ & Source \\
\hline A. vitrina & Copepods & 0.3 & This study \\
& Artemia sp. & 1.3 & \\
A. aequorea & Copepods & 2.1 & Purcell (2003) \\
& Cladocerans & 0.7 & \\
& Larvaceans & 64.5 & \\
\hline
\end{tabular}


rather stagnant due to the usually motionless medusae). The same reservation may apply to clearance rates reported for Sarsia tubulosa, which is also an ambush feeder (Hansson \& Kiørboe 2006).

In all feeding experiments in the present study, the ingestion rate increased linearly with prey concentration, and consequently, the clearance rate must have been constant, in agreement with a number of previous studies on A. aurita (Båmstedt et al. 1994, 2001, Olesen et al. 1994, Olesen 1995) and on S. tubulosa (Daan 1986). Hansson et al. (2005) found that the clearance rate of $S$. tubulosa was constant up to ca. 130 copepods $\mathrm{l}^{-1}$, above which it decreased. This indicates that jellyfish may be well adapted to feed in patches of food, always being able to exploit their clearance capacity. However, Hansson \& Kiørboe (2006) recently observed that $S$. tubulosa may apparently be foodsaturated at considerably lower copepod concentrations.

\section{Temperature effect}

Little is known about the effect of temperature on feeding and growth of jellyfish. We found that an exponential increase in both clearance and maximum specific growth rates with temperature apply to both Aurelia aurita ephyrae and medusae (Fig. 6A,B). Olesen (1995) studied the effect of temperature on the clearance rates of Aurelia aurita between 5 and $20^{\circ} \mathrm{C}$ and found that clearance increased from $200 \mathrm{ml} \mathrm{h}^{-1}$ at $5^{\circ} \mathrm{C}$ to $400 \mathrm{ml} \mathrm{h}^{-1}$ at $10^{\circ} \mathrm{C}$, above which it apparently became constant. Unfortunately, this experiment was made with only one medusa. Temperature effects (between 5 and $19^{\circ} \mathrm{C}$ ) on specific growth rates in A. aurita medusae were studied by Hansson (1997), who found that specific growth rates increase up to about $17^{\circ} \mathrm{C}$, above which rates became constant. The results showed considerable variation at a given temperature, probably because not all individuals were growing at the maximum rate. Furthermore, the initial sizes of the medusae varied, and since specific growth rates decline with size (Fig. 1), this also affected the result. In the present study the effect of temperature was isolated by using the same initial sizes and by feeding the individuals in surplus to ensure maximum growth.

Recently, Widmer (2005) studied the relation between maximum specific growth rate and temperature in Aurelia labiata ephyrae (Fig. 8). The pattern was similar to that found in the present work, although the maximum specific growth rate $\left(40 \% \mathrm{~d}^{-1}\right)$ was obtained at a higher temperature $\left(21^{\circ} \mathrm{C}\right)$ which is probably due to higher temperatures in California $\left(15\right.$ to $\left.22^{\circ} \mathrm{C}\right)$ where A. labiata was studied. Båmstedt et al. (2001) mea-

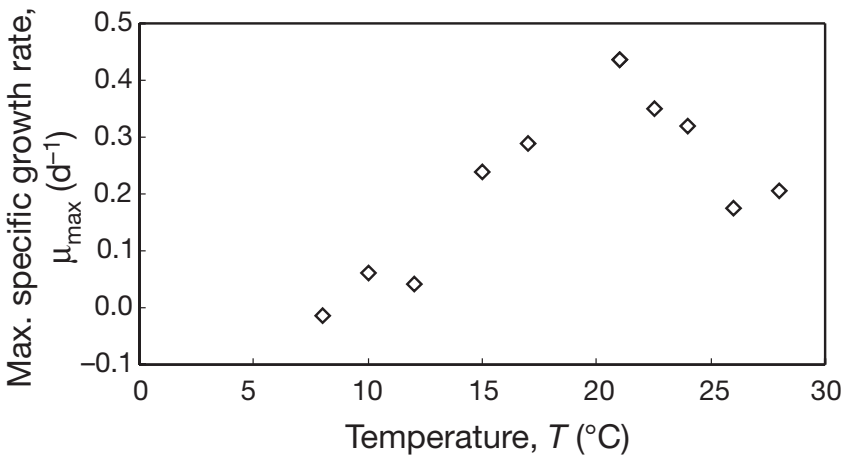

Fig. 8. Aurelia labiata. Maximum specific growth rate of ephyrae as a function of temperature (data from Widmer 2005)

sured growth in $A$. aurita ephyrae fed in surplus at both 15 and $18^{\circ} \mathrm{C}$, and the rates measured (20 and $40 \%$ $\mathrm{d}^{-1}$, respectively) are in agreement with the present growth rates measured at the same temperatures.

\section{Budgets}

In the present study, NGE for Aurelia aurita was about 20 to $30 \%$ (Fig. 7, Table 3), indicating that 70 to $80 \%$ of the assimilated energy may have been used for respiration. This is in fairly good agreement with Olesen et al. (1994) who made an energy budget for A. aurita ephyrae $(D=9 \mathrm{~mm})$ and found that respiration constituted $66 \%$ of assimilated energy. Uye \& Shimauchi (2005) constructed a budget for A. aurita medusae and found that respiration constituted $61 \%$ of the assimilated energy. However, respiration was probably underestimated in the laboratory feeding studies made by Olesen et al. (1994) and Uye \& Shimauchi (2005). Thus, Møller \& Riisgård (2007a) showed that the weight-specific respiration is up to 4 times higher in well fed and fast growing individuals compared to starving individuals. Hence, the respiration rate rapidly decreases to the starvation level within a few hours without food. In the present study, respiration was measured quickly after the last feeding period.

The present budgets were constructed by estimating the lowest concentration resulting in maximum growth as: $C_{\min }=\left(G_{\max }+R_{\mathrm{t}}\right) /(F \times A E)$, which should fit the actual data of maximum specific growth (Figs. $3 \& 4$ ). The unknown factor is the assimilation efficiency, $A E$, which has so far been assumed to be 85 to $90 \%$ (e.g. Olesen et al. 1994, Uye \& Shimauchi 2005). The present study shows, however, that to balance the budget, $A E$ should be lower than 80 to $90 \%$. AE estimated for Aurelia aurita ephyrae was 75 to $85 \%$, close to the assumed values, but $A E$ for adult $A$. aurita was low 
(32 to $37 \%$ ). The low $A E$ values might be due to several reasons. The actual production may be underestimated by assuming that the total production is equal to the growth measured as an increase in umbrella diameter, which does not include all production, e.g. mucus production and released larvae (reproduction). It is assumed that no dissolved organic carbon (DOC) is lost from the medusae, which is unrealistic. Hansson \& Norrman (1995) estimated DOC release to account for 2.5 to $7 \%$ of assimilated carbon in A. aurita. Kremer \& Reeve (1989) found that DOC release accounted for $8 \%$ of assimilated energy in the ctenophore Mnemiopsis sp.

Another factor that may explain a decreasing $A E$ with size is that the jellyfish also keep feeding at high rates at high prey concentrations by displacing partially digested material, as found in the ctenophore Mnemiopsis mccradyi (Reeve et al. 1989). Reeve et al. (1978) found that $A E$ in the ctenophore Pleurobrachia sp. decreased from 74 to $19 \%$ when fed 10 and 100 copepods $\mathrm{l}^{-1}$, respectively. This could be true also in the present study, especially since there was a tendency for higher $A E$ at lower prey concentrations.

Acknowledgements. This study formed part of the EUROGEL project (EVK3-CT-2002-00074). We highly appreciate the constructive criticism made by 4 reviewers, particularly by J. E. Purcell, who revealed her identity.

\section{LITERATURE CITED}

Arai MN (1980) Growth rates of Aequorea medusae. In: Tardent $\mathrm{P}$, Tardent R (eds) Developmental and cellular biology of coelenterates. Elsevier Biomedical Press, Amsterdam, p 163-168

Båmstedt U (1990) Trophodynamics of the scyphomedusae Aurelia aurita. Predation rate in relation to abundance, size and type of prey organism. J Plankton Res 12:125-229

Båmstedt U, Martinussen MB, Matsakis S (1994) Trophodynamics of the scyphozoan jellyfishes, Aurelia aurita and Cyanea capillata, in western Norway. ICES J Mar Sci 51: 369-382

Båmstedt U, Lane J, Martinussen MB (1999) Bioenergetics of ephyra larvae of the scyphozoan jellyfish Aurelia aurita in relation to temperature and salinity. Mar Biol 135:89-98

Båmstedt U, Wild B, Martinussen MB (2001) Significance of food type for growth of ephyrae Aurelia aurita (Scyphozoa). Mar Biol 139:641-650

Berggreen U, Hansen B, Kiørboe T (1988) Food size spectra, ingestion and growth of the copepod Acartia tonsa during development: implications for determination of copepod production. Mar Biol 99:341-352

Colin SP, Costello JH, Klos E (2003). In situ swimming and feeding behaviour of eight co-occurring hydromedusae. Mar Ecol Prog Ser 253:305-309

Costello JH, Colin SP (2002) Prey resource use by coexistent hydromedusae from Friday Harbor, Washington. Limnol Oceanogr 47:934-942

Daan R (1986) Food intake and growth of Sarsia tubulosa (Sars, 1835) with quantitative estimates of predation on copepod populations. Neth J Sea Res 20:67-74
Frandsen KT, Riisgård HU (1997) Size dependent respiration and growth in jellyfish Aurelia aurita. Sarsia 82:307-312

Hansson LJ (1997) Effect of temperature on growth rate of Aurelia aurita (Cnidaria, Scyphozoa) from Gullmarsfjorden, Sweden. Mar Ecol Prog Ser 161:145-153

Hansson LJ (2006) A method for in situ estimation of prey selectivity and predation rate in large plankton, exemplified with the jellyfish Aurelia aurita (L.). J Exp Mar Biol Ecol 326: 113-126

Hansson LJ, Norrman B (1995) Release of dissolved organic carbon (DOC) by the scyphozoan jellyfish Aurelia aurita and its potential influence on the production of planktonic bacteria. Mar Biol 121:527-532

Hansson LJ, Kiørboe T (2006) Prey-specific encounter rates and handling efficiencies as causes of prey selectivity in ambush-feeding hydromedusae. Limnol Oceanogr 51: 1849-1858

Hansson LJ, Moeslund O, Kiørboe T, Riisgård HU (2005) Clearance rates of jellyfish and their potential predation impact on zooplankton and fish larvae in a neritic ecosystem (Limfjorden, Denmark). Mar Ecol Prog Ser 304:117-131

Ishii H, Båmstedt U (1998) Food regulation of growth and maturation in a natural population of Aurelia aurita (L.). J Plankton Res 20:805-816

Kramp PL (1961) Synopsis of the medusae of the world. J Mar Biol Assoc UK 40:1-469

Kremer P, Reeve MR (1989) Growth dynamics of a ctenophore (Mnemiopsis) in relation to variable food supply. II. Carbon budgets and growth model. J Plankton Res 11:553-574

Matsakis S, Conover RJ (1991) Abundance and feeding of medusae and their potential impact as predators on other zooplankton in Bedford Basin (Nova Scotia, Canada) during spring. Can J Fish Aquat Sci 48:1419-1430

Möller H (1979) Significance of coelenterates in relation to other plankton organisms. Meeresforsch 27:1-18

Möller H (1984) Reduction of larval herring populations by jellyfish predation. Science 224:621-622

Møller LF, Riisgård HU (2007a) Respiration in the scyphozoan jellyfish Aurelia aurita and two hydromedusae (Sarsia tubulosa and Aequorea vitrina): effect of size, temperature and growth. Mar Ecol Prog Ser 330:149-154

Møller LF, Riisgård HU (2007b) Population dynamics, growth and predation impact of the common jellyfish Aurelia aurita and two hydromedusae, Sarsia tubulosa and Aequorea vitrina, in Limfjorden (Denmark). Mar Ecol Prog Ser, 346: 153-165

Muxagata E, Williams JA, Shaeder M (2004) Composition and temporal distribution of cirripede larvae in Southampton Water, England, with particular reference to the secondary production of Elminius modestus. ICES J Mar Sci 61: 585-595

Olesen NJ (1995) Clearance potential of jellyfish Aurelia aurita and predation impact on zooplankton in a shallow cove. Mar Ecol Prog Ser 124:63-72

Olesen NJ, Frandsen K, Riisgård HU (1994) Population dynamics, growth and energetics of jellyfish Aurelia aurita in a shallow fjord. Mar Ecol Prog Ser 105:9-18

Purcell JE (1989) Predation on fish larvae and eggs by the hydromedusa Aequorea victoria at a herring spawning ground in British Columbia. Can J Fish Aquat Sci 46: 1415-1427

Purcell JE (1991) Predation by Aequorea victoria on other species of potentially competing pelagic hydrozoans. Mar Ecol Prog Ser 72:255-260

Purcell JE (1997) Pelagic cnidarians and ctenophores as predators: selective predation, feeding rates, and effects on prey populations. Ann Inst Oceanogr Paris 73:125-137 
Purcell JE (2003) Predation on zooplankton by large jellyfish, Aurelia labiata, Cyanea capillata and Aequorea aequorea, in Prince William Sound, Alaska. Mar Ecol Prog Ser 246: 137-152

Purcell JE, Grover JJ (1990) Predation and food limitation as causes of mortality in larval herring at a spawning ground in British Columbia. Mar Ecol Prog Ser 59:55-61

Reeve MR, Walter MA, Ikeda T (1978) Laboratory studies of ingestion and food utilization in lobate and tentaculate ctenophores. Limnol Oceanogr 23(4):740-751

Reeve MR, Syms MA, Kremer P (1989) Growth dynamics of a ctenophore (Mnemiopsis) in relation to variable food supply. I. Carbon biomass, feeding, egg production, growth and assimilation efficiency. J Plankton Res 11:535-552

Riisgård HU (2007) Feeding behaviour of the hydromedusa Aequorea vitrina. Sci Mar 71:395-404

Russell FS (1953) The medusae of the British Isles. Cambridge University Press, Cambridge

Schneider G (1988) Chemische Zusammensetzung und Biomasseparameter der Ohrenqualle Aurelia aurita. Helgol Meeresunters 42:319-327

Schneider G (1989) Estimation of food demands of Aurelia

Editorial responsibility: Howard Browman (Associate Editorin-Chief), Storebø, Norway aurita medusae populations in the Kiel Bight/Western Baltic. Ophelia 31:17-27

Schneider G, Behrends G (1994) Population dynamics and the trophic role of Aurelia aurita medusae in the Kiel Bight and western Baltic. ICES J Mar Sci 51:359-367

Sullivan BK, Garcia JR, Klein-MacPhee G (1994) Prey selection by the scyphomedusan predator Aurelia aurita. Mar Biol 121:335-341

Sullivan BK, Suchman CL, Costello JH (1997) Mechanics of prey selection by ephyrae of the scyphomedusa Aurelia aurita. Mar Biol 130:213-222

Szyper JP (1989) Nutritional depletion of the aquaculture feed organisms Euterpina acutifrons, Artemia sp. and Brachionus plicatilis during starvation. J World Aquac Soc 20: 162-169

Uye S, Shimauchi H (2005) Population biomass, feeding, respiration and growth rates, and carbon budget of the scyphomedusa Aurelia aurita in the Inland Sea of Japan. J Plankton Res 27:237-248

Widmer CL (2005) Effects of temperature on growth of northeast Pacific moon jellyfish ephyrae, Aurelia labiata (Cnidaria: Scyphozoa). J Mar Biol Assoc UK 85:569-573

Submitted: September 8, 2006; Accepted: March 3, 2007 Proofs received from author(s): September 10, 2007 